\title{
Epidémies, drogues et prévention: que d'émotions!
}

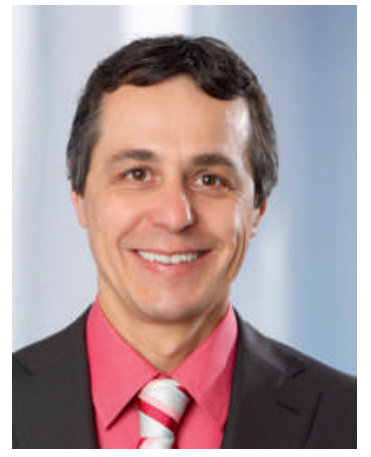

La guerre entre les microbes et l'être humain se poursuit depuis la nuit des temps: comme des vagues qui brisent la côte, les microbes modèlent notre existence, dans une interaction qui ne finit jamais. Les épidémies ont toujours été une préoccupation de notre Etat fédéral, dès sa naissance en 1848 . Lors de la session parlementaire de printemps, elles étaient de nouveau au centre du débat politique: nous avons mis à jour, pour la deuxième fois dès sa naissance le 2 juillet 1886, la loi contre les épidémies offrant un danger général (10.107). C'est en effet il y a 136 ans, dans un climat de grandes découvertes scientifiques (en 1876, Robert Koch démontrait la relation de cause à effet entre le germe de l'anthrax et la maladie), que notre jeune Parlement décida de voter la première loi fédérale contre les épidémies. Les cantons avaient confié cette tâche à la Confédération, sachant que les microbes ne s'arrêtent pas aux frontières politiques. Parmi les effets de cette loi, je rappelle volontiers la naissance des médecins cantonaux. Une grave épidémie de typhus survenue à Zermatt en 1963, qui avait touché plus de 400 personnes dont plusieurs avaient succombé, conduisait en 1970 à la première révision totale. Plusieurs révisions partielles ont eu lieu par la suite, jusqu'à cette deuxième révision totale, nécessaire pour faire face aux menaces du XXIe siècle.

La nouvelle loi présente un modèle à trois échelons, selon que la situation est normale, particulière ou extraordinaire. Elle confère davantage de responsabilité à la Confédération dans la loi, mais seulement lors de situations particulières et uniquement par décision du Conseil fédéral. L'autre casus belli qui a fait grimper les décibels dans la salle a été la modification de la norme pénale sur la propagation d'une maladie dangereuse à autrui. Les sanctions prononcées en Suisse pour la propagation du VIH/Sida ont suscité un vif débat. La disposition a été modifiée en ce sens qu'une personne n'est pas punissable lorsqu'elle transmet une maladie si, avant la transmission, elle a informé l'autre personne du risque concret d'infection. Finalement, la loi sur les épidémies a été acceptée par une large majorité du National (152 voix contre 4). La FMH est satisfaite.

\section{La pénalisation de la consommation de cannabis reste, mais la façon de sanctionner change!}

Autre thème passionnant: la loi sur la prévention (09.076). Suite au refus du Conseil des Etats d'entrer en matière en décembre 2011, le National a dû revenir sur la question. Heureusement (aux yeux de la FMH), une majorité de 106 voix contre 79 a confirmé la volonté de créer cette loi pour améliorer l'efficience de la prévention. C'est donc à nouveau au Conseil des Etats de se prononcer, en juin prochain. Un OUI permettrait à la loi de voir le jour, un NON serait alors définitif et... l'on en discuterait peut-être à nouveau en 2030!

Dernier thème - tout aussi fascinant - a été celui de la «drogue», notamment du cannabis (04.439). L'idée du PDC

\section{La nouvelle loi contre les épidémies confère davantage de responsabilité à la Confédération, qui devra définir des objectifs stratégiques nationaux et coor- donner tout le dispositif, alors que l'exécution reste dans les mains des cantons.}

(OFSP), qui devra définir des objectifs stratégiques nationaux et coordonner tout le dispositif, alors que l'exécution reste dans les mains des cantons. Les principes de l'autodétermination et de la responsabilité individuelle sont inscrits dans la loi. Le débat au National a connu deux flambées d'émotions lorsqu'il a été question des dispositions sur les vaccinations et de l'art. $231 \mathrm{ch} .1 \mathrm{du}$ Code pénal suisse (contre la transmission de maladies infectieuses). La rhétorique classique des adversaires des vaccins, transversale à tous les partis - mais plus forte à gauche - a trouvé une majorité pour biffer le droit des cantons à déclarer obligatoire une vaccination sur leur territoire en situation normale. La possibilité reste ancrée
Suisse d'introduire des amendes d'ordre (comme dans la circulation routière) pour punir la consommation chez les adultes, a trouvé une majorité de 111 voix contre 65 au National, malgré une vive opposition de l'UDC. L'amende d'ordre a été fixée à Fr. 200.- et est applicable seulement si le consommateur porte sur lui un max. de $10 \mathrm{~g}$ de cannabis. La voie pénale ordinaire demeure applicable à tous les autres cas. La pénalisation de la consommation reste, mais la façon de sanctionner change! Une petite révolution: je suis curieux des décisions du Conseil des Etats. La FMH soutient cette voie.

Dr Ignazio Cassis, vice-président de la FMH et conseiller national 